\title{
Spectral Estimation of Soil Moisture Content using Semi Empirical Soil Model in the 0.4-2.5 um Domain
}

\author{
Saima Ansari ${ }^{1}$ \\ Department of CS and IT, \\ Dr. Babasaheb Ambedkar \\ Marathwada University \\ Aurangabad, Maharashtra, \\ India
}

\author{
Ashwini Dilip Padmanabhi ${ }^{2}$ \\ Department of CS and IT, \\ Dr. Babasaheb Ambedkar \\ Marathwada University \\ Aurangabad, Maharashtra, \\ India
}

\author{
Dr. Ratnadeep R. Deshmukh ${ }^{3}$ \\ Department of CS and IT, \\ Dr. Babasaheb Ambedkar \\ Marathwada University \\ Aurangabad, Maharashtra, \\ India
}

\begin{abstract}
Soil moisture content (SMC) plays a key role in the crop production as it act as a nutrient and serves as solvent for other nutrients such as sodium, potassium, carbon, nitrogen. Soil characteristics can be analyzed using spectral reflectance of the soil in the 0.4-2.5 um domain. 25 soil samples of different textures have been collected from four different areas of Aurangabad city, Maharashtra. Soil spectral reflectances were measured in the laboratory with an ASD (Analytical Spectral Devices) Fieldspec-Pro spectroradiometer in the $(0.4-2.5 \mu \mathrm{m})$ spectral domain. Dataset consists of 150 spectral refelctances (six SMC level i.e. $0 \%$, $12 \%$, $16 \%, 21 \%, 26 \%$ and 30\% for each sample). Existing spectral indices like Normalized Soil Moisture Index (NSMI) and Water Index SOIL (WISOIL) are sensitive to water vapor absorption. Our study has been focused on to overcome existing spectral indices limitation. To accomplish this, new spectral index i.e. Normalized Index of NSWIR domain for Smc estimatiOn from Linear regression (NINSOL) has been implemented on the dataset. Semi empirical soil model has been used to estimate SMC as it is robust against soil sample texture. From the results, it is observed that NINSOL operates in $2056 \mathrm{~nm}$ and $2263 \mathrm{~nm}$ spectral range. Performance comparison has been done among NSMI ,WISOIL and NINSOL. NSMI and WISOIL led to $\mathrm{R}^{2}$ value as 0.79 , 0.81 respectively and 6.6, 6.2 RMSE value. NINSOL produces better results than existing indices as $\mathrm{R}^{2}$ value of 0.85 and 5.6 RMSE value.
\end{abstract}

Keywords: Soil moisture content, spectral reflectance, spectral indices, semi empirical soil model, NINSOL, regression.

\section{INTRODUCTION}

SMC is most important nutrient present in the soil. It makes a significant impact on plant growth, percolation, evaporation, microbiological decomposition of the soil organic matter and also on heat exchange. Usually, soil moisture is affected by soil physical properties such as soil color, soil texture features $[1,2]$, structure and bulk density. It is significant parameter for several applications in hydrology, horticulture, agriculture and meteorology. It influences plant growth, percolation, evaporation and heat exchange. Description of SMC is very useful for many agricultural applications like irrigation system, plant stress and improving crop yield. Remote sensing techniques have several advantages in comparison with others classical methods (gravimetric, electromagnetic, thermal...) for monitoring SMC, as they provide better temporal and spatial coverage [3].

In agriculture point of view, soil moisture information is essential for many applications like irrigation scheduling, plant stress and improving crop yield. Soil moisture also determines the partitioning of net radiation into latent and sensible heat components in the field of meteorology. Therefore, accurate soil moisture estimates are essential in several applications as to examine the effect of climate change on land surface hydrological variables such as soil moisture, infiltration fluxes, runoff and surface temperature caused by changes in heat fluxes and to quantify the amount and variability of regional water resources in water limited regions of the world on seasonal.
E.E.Abdel-hady* et al. [4], conducted experiments in which soil moisture content was measured using X-ray spectroscopy system. It is concluded that the bulk density at dry and wet stages remain unaffected as there is no rearrangement during wetting and drying process. K. Grote et al. [5] used Ground Penetrating Radar (GPR) to measure SMC using $450 \& 900$ $\mathrm{MHz}$ antennas. It is observed that multi-frequency GPR should be used to calculate soil moisture content at different depths. Active microwave sensor is used at high spatial resolution due to its sensitivity to the dielectric constant of soil and its moisture [6]. Hyperspectral imagery can be used to estimate the SMC but its performance depends on the crust, soil color and texture. [6-9]

Gaussian spectral models presented by Michael [10] presented an approach fitting an inverted Gaussian function to estimate moisture content. It is concluded that both area and amplitude of inverted Gaussian has high relationship. Fusun Balik Sanli et al. [11] gathered SAR data by RADARSAT, ASAR and PALSAR satellite images of Menemen Town, Izmir. The correlations between the soil moisture content and backscattering of ASAR, RADARSAT-1 and PALSAR images were found $76 \%, 81 \%$ and $86 \%$ respectively. Marion Pause et al. [12] concluded that data obtained from inversion of airborne \& satellite L-band radiometer provides estimation of soil moisture. They evaluated effect of Leaf Area Index (LAI) against airborne L-band brightness temperature of crop canopies. Jian Peng et al. [13] evaluated Discrete Wavelet Transform (DWT) to find SMC. 13 different mother wavelet s along with six decomposition levels from 5-10 are identified 
for selected data. It is concluded that DWT reduced the hyperspectral dimensionality, thus giving better results than existing methods.

Angström A.[14] conducted laboratory experiments and concluded that soil spectral reflectance shows traces of soil moisture content. In 1987, American Society for Testing and Materials (ASTM) [15] published standard test method which uses microwave oven for estimating soil moisture content. It stated that it is alternative to conventional oven. Bach, H.et al. [16] confirmed_the behavior proposed by Angstrom and then spectral reflectance is used to develop soil moisture content approaches. Lesaignoux, A. et al. [17] proposed a semiempirical soil model which is robust to soil texture. A priori soil classes are identified and then soil samples were linked them.

Soren-Nils Haubrock" et al. [18] studied Normalized Soil Moisture Index (NSMI) to Hyperspectral data. They concluded that NSMI is best suitable to estimate soil moisture content from high spectral resolution remote sensing data. Haubrock, S. et al. [19] proposed new approach called NSMI in spectral range $(350-2500 \mathrm{~nm})$ which is robust against many influencing factors. From the results, it is concluded that NSMI remains unchanged under effect of surface crusts or substrate heterogeneity. Attila Nagy et al. [20] used spectral reflectance of soil samples to estimate SMC. The reflectance curve of sand \& sandy loam soil is linear with the wavelength $\&$ gradual increase of clay soil sample curves. Sophie Fabre et al. [21] recorded spectral reflectance of the collected soil samples in the reflective domain $(0.4-2.5 \mu \mathrm{m})$. Then they compared performance of new approaches to calculate SMC against available SMC estimation indices like NSMI and WISOIL. Lobell et al. [22] collected four bare soil spectra and applied an exponential model onto it. They concluded that SMC is sensitive to SWIR domain.

\section{DESCRIPTION OF THE REFERENCE DATA SET}

\subsection{Database Collection}

Soil spectral reflectances were measured in the laboratory with an ASD (Analytical Spectral Devices) Fieldspec-Pro spectroradiometer in the $(0.4-2.5 \mu \mathrm{m})$ spectral domain with a spectral resolution of $3 \mathrm{~nm}$ in the $(0.4-1.0 \mu \mathrm{m})$ domain and of $10-12 \mathrm{~nm}$ in the $(1.0-2.5 \mu \mathrm{m})$ domain. The database is collected from 4 different areas near Aurangabad city, Maharashtra. It is composed of 25 natural soil samples, covering different ranges of texture (clay, loam, sandy). Spectral signature of each soil sample was collected at six different SMC level, thus six spectral reflectance of each sample. Thus, our dataset consists of total 150 spectral reflectance of soil samples. Detailed description of the data set along with their Munsell color code is described in table 1.
Table 1. Detailed description of data set (Munsell color code [24]

\begin{tabular}{|l|c|c|c|c|}
\hline \multicolumn{2}{|c|}{ Description } & \multicolumn{3}{c|}{ Munsell Color Code } \\
\hline Area Name & Number & Hue & Value & Chroma \\
\hline Himayat \\
Baugh(6) & 3 & $5 \mathrm{Y}$ & 7 & 1 \\
\cline { 2 - 5 } & 1 & $2.5 \mathrm{Y}$ & 7 & 6 \\
\cline { 2 - 5 } & 2 & $2.5 \mathrm{Y}$ & 6 & 6 \\
\hline Dr.BAMU \\
Campus(5) & 3 & $5 \mathrm{Y}$ & 5 & 4 \\
\cline { 2 - 5 } Himayat & 2 & $5 \mathrm{Y}$ & 5 & 3 \\
\cline { 2 - 5 } Nagar(8) & 4 & $2.5 \mathrm{Y}$ & 4 & 4 \\
\cline { 2 - 5 } & 2 & $10 \mathrm{YR}$ & 4 & 2 \\
\hline Pimpalgaun(6) & 3 & $2.5 \mathrm{Y}$ & 5 & 1 \\
\cline { 2 - 5 } & 3 & $2.5 \mathrm{Y}$ & 8 & 3 \\
\hline
\end{tabular}

\subsection{Measurement Method}

Each soil sample was oven dried (at $105^{\circ} \mathrm{C}$ ) until fully dried situation. After $24 \mathrm{~h}$ in the oven, it is assumed that soil sample is fully dried. Then these samples are artificially wetted at different soil moisture levels: (percentage of dry weight): $12 \%$, $16 \%, 21 \%, 26 \%, 30 \%$ and successive spectral reflectance of soil samples at different moisture level were taken. In our dataset, there are 25 soil samples, each sample has 6 reflectance spectrum thus resulting in total 150 spectral signature in our dataset. Figure 1 illustrates the observed spectral behavior of the dry sample at different soil moisture content in the VISible (VIS; $(0.4-0.8 \mu \mathrm{m})$ ) and Near and Shortwave InfraRed (NSWIR; $(0.8-2.5 \mu \mathrm{m})$ ) spectral domains.

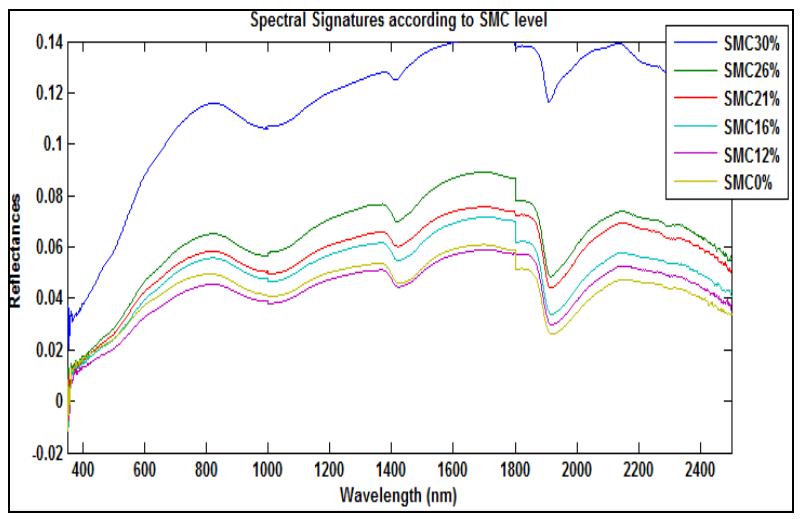

Figure 1. Spectral reflectance of soil sample at different SMC levels

\section{DESCRIPTION OF THE METHODS TO ESTIMATE THE SOIL MOISTURE CONTENT}

\subsection{Spectral Indices}

Most widely used spectral indices are Normalized Soil Moisture Index (NSMI) and Water Index SOIL (WISOIL).These spectral indices are operated at that wavelength range which are sensitive to water vapor absorption (at 1.2, 1.4, and $1.9 \mu \mathrm{m}$ ). Thus producing ineffective or underperforming results (see table 2).

The wavelengths at $1.8 \mu \mathrm{m}$ and $1.45 \mu \mathrm{m}$ operated respectively by NSMI and WISOIL are located at the border of the atmospheric water vapor absorption band.(see figure 2) 
Table 2. Existing spectral indices to estimate SMC

\begin{tabular}{|l|l|l|}
\hline $\begin{array}{l}\text { Spectral } \\
\text { Index }\end{array}$ & $\begin{array}{l}\text { Specific Spectral } \\
\text { Bands }\end{array}$ & Formulation \\
\hline NSMI & $1.800 \mu \mathrm{m} ; 2.119 \mu \mathrm{m}$ & $\rho_{1.8}-\rho_{2.119} / \rho_{1.8}+\rho_{2.1} 19$ \\
\hline WISOIL & $1.30 \mu \mathrm{m} ; 1.45 \mu \mathrm{m}$ & $\rho_{1.45} / \rho_{1.30}$ \\
\hline
\end{tabular}

The WISOIL and NSMI performance is then very dependent on the quality of the atmosphere compensation processing. Due to drawback of existing spectral indices, there is need to define new spectral index.
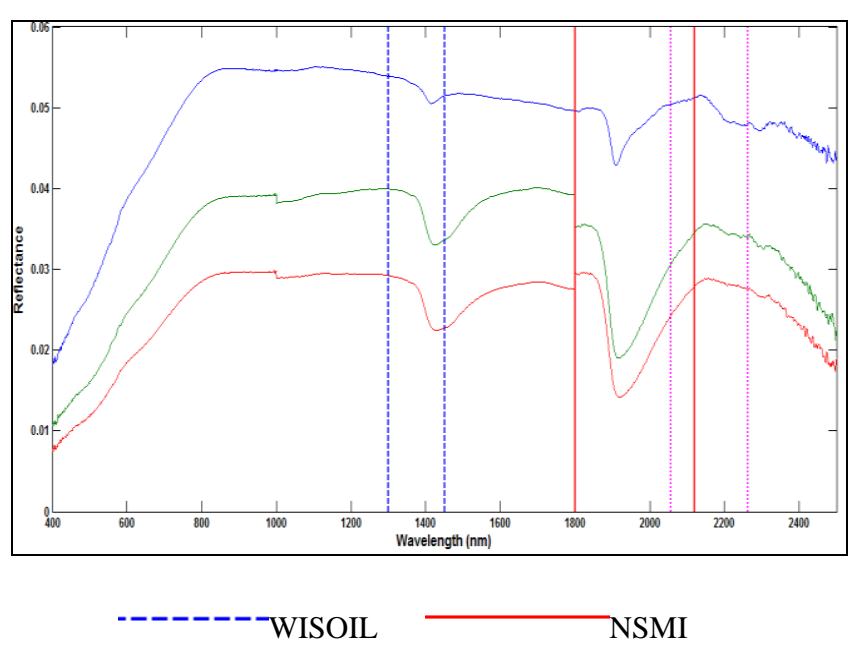

NINSOL(new proposed index)

Figure 2. Spectral indices

\subsection{Description of the Soil Empirical Spectral Model}

Various spectral soil models exist to estimate soil moisture content. But, all these modes uses soil texture to estimate SMC. To overcome this limitation, the proposed model is based on an a priori soil classification defined according to the global spectral shape of the dry soil reflectances [16]. The soil samples with the same spectral behavior are then grouped together in a priori spectral classes. [16]. The semi-empirical soil model linking the spectral reflectance to the SMC for a given a priori soil class defined by the Table 2 , is retained. Its analytical formulation is the following:

$$
\rho_{S M C_{g}}^{l}(\lambda)=a_{l}(\lambda) \cdot S M C_{g}^{2}+b_{l}(\lambda) \cdot S M C_{g}+c_{l}(\lambda)
$$

where $l$ designs the soil spectral class, $a, b$ and $c$ are the spectral coefficients of the polynomial function in the solar domain.

\subsection{A priori Classification}

Dry soil samples were used to define a priori class. These can be obtained by grouping spectral reflectance of soil depending upon their spectral shape in VIS and NSWIR domain. In our data set, three groups i.e. $1 \mathrm{~V}, 2 \mathrm{~V}, 3 \mathrm{~V}$ groups are obtained in VIS domain and four groups i.e. $1 \mathrm{~N}, 2 \mathrm{~N}, 3 \mathrm{~N}, 4 \mathrm{~N}$ groups were identified in NSWIR domain .These groups in each domain leads to formation of six a priori classes defined in table 3 and illustrated in figure 3.
Table 3. The a priori spectral classification

\begin{tabular}{|c|c|c|c|}
\hline \multicolumn{2}{|c|}{ Class } & \multicolumn{2}{c|}{$\begin{array}{c}\text { Spectral behavior } \\
\text { groups }\end{array}$} \\
\hline Number & Soil number & VIS & NSWIR \\
\hline 1 & 4 & $1 \mathrm{~V}$ & $1 \mathrm{~N}$ \\
\hline 2 & 5 & $1 \mathrm{~V}$ & $4 \mathrm{~N}$ \\
\hline 3 & 2 & $2 \mathrm{~V}$ & $2 \mathrm{~N}$ \\
\hline 4 & 3 & $2 \mathrm{~V}$ & $3 \mathrm{~N}$ \\
\hline 5 & 3 & $3 \mathrm{~V}$ & $3 \mathrm{~N}$ \\
\hline 6 & 8 & $3 \mathrm{~V}$ & $4 \mathrm{~N}$ \\
\hline
\end{tabular}

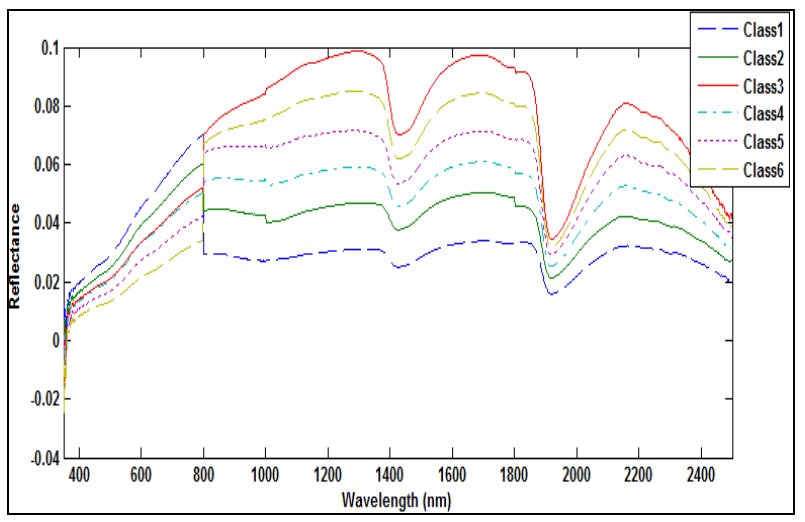

Figure 3. Six a priori spectral classes

Haubrock et al. [19] proposed procedure for new index for estimation to soil moisture content which is robust against water absorption effect.

According to this procedure, the normalized ratio $X_{\text {norm }}\left(\lambda_{\mathrm{i}}\right.$, $\lambda_{j}$ ) defined by the following equation:

$$
X_{n o r m}\left(\lambda_{i}, \lambda_{j}\right)=\rho\left(\lambda_{i}\right)-\rho\left(\lambda_{j}\right) / \rho\left(\lambda_{i}\right)+\rho\left(\lambda_{j}\right) .
$$

where $\rho\left(\lambda_{\mathrm{i}}\right)$ and $\rho\left(\lambda_{\mathrm{j}}\right)$ respectively represent the reflectance values at the wavelengths $\lambda_{\mathrm{i}}$ and $\lambda_{\mathrm{j}}$ belonging to the reflective domain $(0.4-2.5 \mu \mathrm{m})$.

The coefficient of determination for the linear regression [23] between SMC and a quantity $\mathrm{X}_{\text {norm }}\left(\lambda_{\mathrm{i}}, \lambda_{\mathrm{j}}\right)$, derived from the spectral reflectance, is plotted in a matrix where the first wavelength value $\lambda_{\mathrm{i}}$ is referred to by the abscissa axis and the second wavelength $\lambda_{j}$ is referred to by the ordinate axis (Equation (2)). This matrix is called regression matrix, shown on Figure 4 and the color scale from 0 to 0.85 represents the corresponding $\mathrm{R}^{2}$ value.

SMC are very sensitive to wavelength pairs $\left(\lambda_{\mathrm{i}}, \lambda_{\mathrm{j}}\right)$ are located in the spectral range $(1-2.5 \mu \mathrm{m})$. The wavelength pairs leading to the highest determination coefficients between the SMC and the quantity $X_{n o r m}\left(\lambda_{i}, \lambda_{j}\right)$, are used to construct these new indices:

- $\quad 2056 \mathrm{~nm}$ and $2263 \mathrm{~nm}$ for $\mathrm{X}_{\mathrm{norm}}\left(\lambda_{\mathrm{i}}, \lambda_{\mathrm{j}}\right): \mathrm{R}^{2}=85 \%$

These results lead to the following spectral index:

- Normalized Index of NSWIR domain for Smc estimatiOn from Linear regression (NINSOL)

NINSOL $=\rho\left(\lambda_{2056}\right)-\rho\left(\lambda_{2263}\right) / \rho\left(\lambda_{2056}\right)+\rho\left(\lambda_{2263}\right)$ 


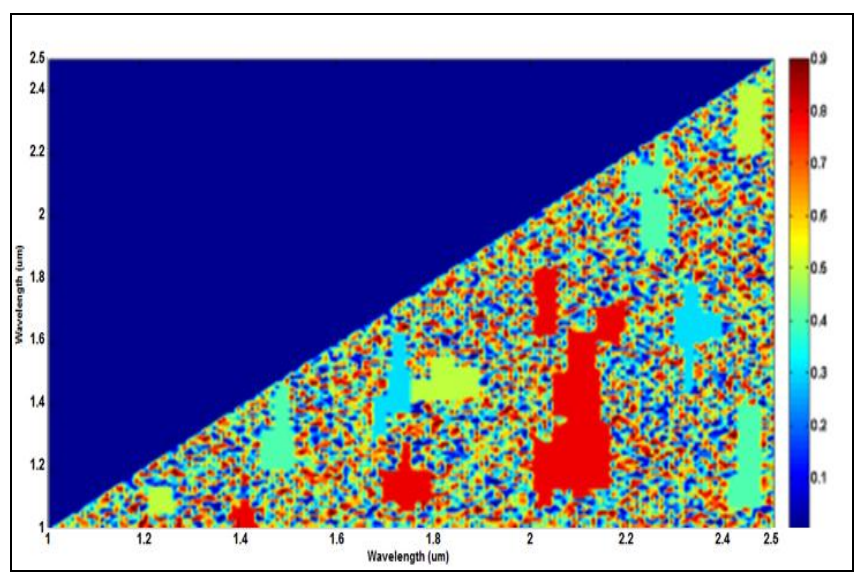

Figure 4. Determination matrix for $X_{n o r m}\left(\lambda_{i}, \lambda_{j}\right)$ derived by linear regression

\section{RESULTS AND DISCUSSION}

\subsection{Performance Analysis}

Spectral indices and semi empirical soil model is implemented to estimate SMC on described data set. Their performance is evaluated by two metrics i.e. coefficient of determination $\left(\mathrm{R}^{2}\right)$ and Root Mean Square Error (RMSE). The dataset is divided in two groups. first calibration data set to calibrate the methods and second validation data set is used to the validation based on $80 \%$ - $20 \%$ pattern i.e. 120 spectral reflectance in calibration data set and 30 remaining spectral reflectance in validation data set. For each method, the comparison process is as follows:

- Calibration stage: The measured spectral reflectance and the corresponding SMC of the calibration data set are used to achieve the linear regression between the index values and the SMC for NINSOL, WISOIL, NSMI.

- Validation stage: The SMC is estimated with the validation data. The quality of the SMC estimation is assessed by computing the $\mathrm{R}^{2}$ and the RMSE.

The RMSE is expressed as follows:

$$
R M S E=\sqrt{\sum\left(S M C_{m e s}^{i}-S M C_{e s t}^{i}\right)^{2} / N}
$$

where $S M C_{i}{ }^{\text {est }}$ is the estimated SMC for the soil sample $i$, $S M C_{i}{ }^{\text {mes }}$ is the measured SMC for the same sample $i$ and $\mathrm{N}$ is the number of samples.

\subsection{Results}

Table 4 shows performance metrics i.e. $\mathrm{R}^{2}$ and RMSE on the validation data set and measured SMC by semi empirical model for each a priori soil spectral class. From the results, it is concluded that $\mathrm{R}^{2}$ is better than 0.83 and RMSE ranges between $4 \%$ and $6 \%$.
Table 4. $\mathbf{R}^{2}$ and RMSE for each a priori class

\begin{tabular}{|c|c|c|}
\hline Soil Spectral Class & $\mathbf{R}^{\mathbf{2}}$ & RMSE \\
\hline 1 & 0.89 & 4.4 \\
\hline 2 & 0.88 & 4.7 \\
\hline 3 & 0.87 & 6.2 \\
\hline 4 & 0.90 & 5.5 \\
\hline 5 & 0.93 & 5.2 \\
\hline 6 & 0.83 & 6.0 \\
\hline
\end{tabular}

Performance comparison for existing and proposed spectral indices is given in table 5. NSMI and WISOIL gives 0.79 and 0.81 values for $\mathrm{R}^{2}$ and 6.6, 6.2 RMSE values respectively. The new proposed index NINSOL shows better performance than existing spectral indices i.e. $\mathrm{R}^{2}$ value of 0.85 and 5.6 RMSE value.

Table 5. Methods and their performance

\begin{tabular}{|l|l|l|}
\hline Method & $\mathbf{R}^{\mathbf{2}}$ & RMSE \\
\hline NSMI & 0.79 & 6.6 \\
\hline WISOIL & 0.81 & 6.2 \\
\hline NINSOL & 0.85 & 5.6 \\
\hline
\end{tabular}

The results for WISOIL and NINSOL are illustrated in the figure 5 and figure 6 respectively.

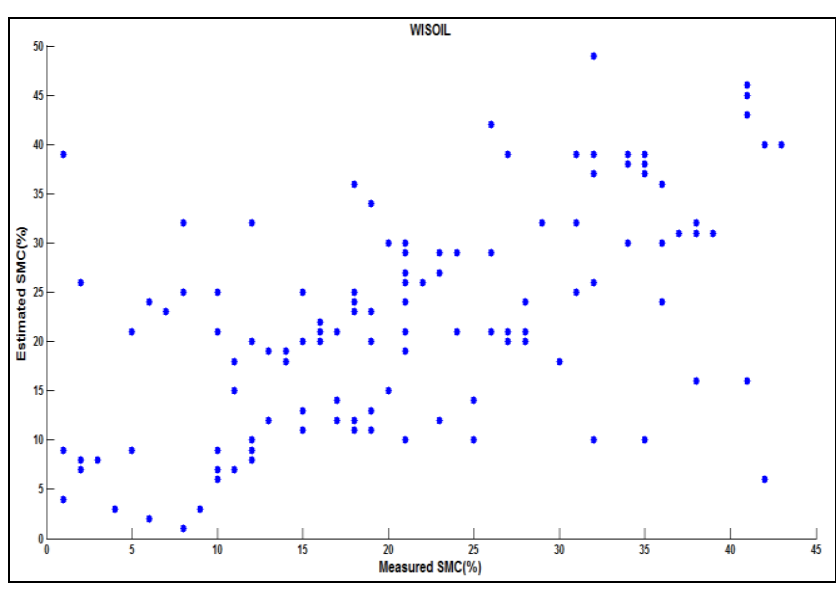

Figure 5 .Estimated SMC according to measured SMC for WISOIL

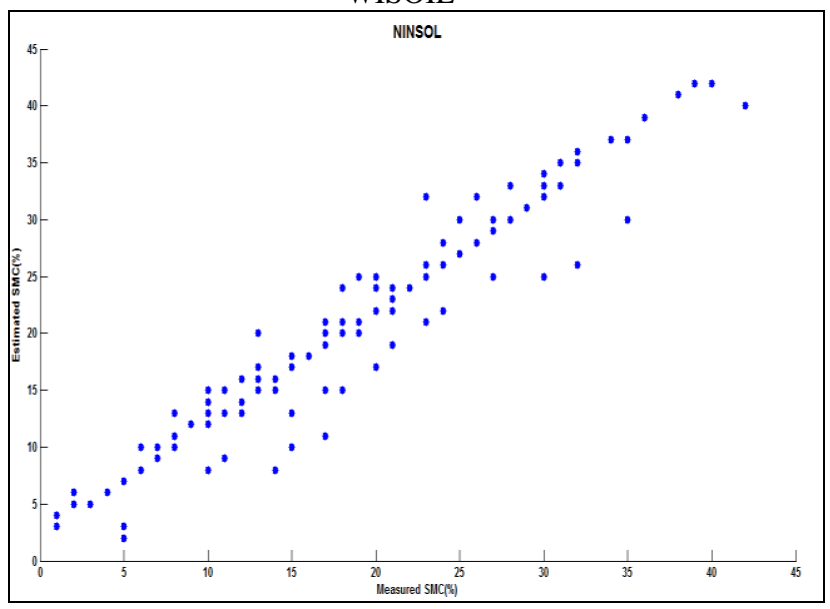

Figure 6. Estimated SMC according to measured SMC for NINSOL 


\section{CONCLUSION}

Based on the results of the study, soil moisture content can be efficiently estimated with the help of spectral signature of soil sample in reflective spectral domain (0.4-2.5 um). Existing methods takes soil texture as important parameter for estimation of soil moisture content. Existing spectral indices i.e. NSMI and WISOIL operates in the range of wavelength which are sensitive to water vapor absorption. Semi empirical soil model overcomes limitation of existing soil models. It defines a priori classes for data set and then soil samples were linked to these a priori classes to estimate SMC. It is observed that soil moisture content is sensitive to the spectral range 1$2.5 \mathrm{um}$. Thus, study of soil samples has been carried out in this range by determining the regression matrix for normalized difference of spectral reflectance by linear regression. New proposed index i.e. NINSOL is robust and remains less affected by water vapor absorption. NINSOL operates in $2056 \mathrm{~nm}$ and $2263 \mathrm{~nm}$ spectral range. Performance analysis has been done on NSMI, WISOIL and NINSOL. NSMI led to $\mathrm{R}^{2}$ value of 0.79 and RMSE value of 6.6 . While WISOIL produces $\mathrm{R}^{2}$ value as 0.81 and 6.2 RMSE value. NINSOL produces better results than existing indices as $\mathrm{R}^{2}$ value of 0.85 and RMSE value of 5.6.

\section{ACKNOWLEDGMENTS}

This work is supported by Department and Science and Technology under the Funds for Infrastructure under Science and Technology (DST-FST) with sanction no. SR/FST/ETI340/2013 to Department of Computer Science and Information Technology. Dr. Babasaheb Ambedkar Marathwada University, Aurangabad, Maharashtra, India. The authors would like to thank Department and University Authorities for providing the infrastructure and necessary support for carrying out the research.

\section{REFERENCES}

[1] Nocita, M.; Stevens, A.; Noon, C.; Wesemae, B.V. 2013. Prediction of soil organic carbon for different levels of soil moisture using Vis-NIR spectroscopy. Geoderma ,199, 37-42.

[2] Ben-Dor, E.; Chabrillat, S.; Demattê, J.A.M.; Taylor, G.R.; Hill, J.; Whiting, M.L.; Sommer, S. 2009. Using Imaging Spectroscopy to study soil properties. Remote Sens. Environ., 113, 538-555.

[3] 6. Bryant, R.; Thoma, D.; Moran, S.; Holifield, C.; Goodrich, D.; Keefer, T.; Paige, G.; Williams, D.; Skirvin, S. 2003. Evaluation of Hyperspectral, Infrared Temperature and Radar Measurements for Monitoring Surface Soil Moisture. In Proceedings of the First Interagency Conference on Research in the Watersheds, Benson, Arizona, 27-30 , pp. 528-533.

[4] E.E.Abdel-hady*, A..M.A..EL-Sayed and H.B.AIaa. 1996. Determination Of Moisture Content And Natural Radioactivity In Soils Using Gamma Spectroscopy. Third Radiation Pkytk* Conf* AUMinia.

[5] K. Grote, S. Hubbard , Y. Rubin. 2003. Field-scale estimation of volumetric water content $\mathrm{u}$ sing ground penetrating radar ground wave techniques. Water Resources Research, VOL. 39, NO. 11, 1321.

[6] Shi, J.; Wang, J.; Hsu, A.Y; O’Neill, P.E; Engman, E.T. 1997. Estimation of bare surface soil moisture and surface roughness parameter using L-band SAR image data. IEEE Trans. Geosci. Remote Sens., 35, 1254-1266.
[7] Ben-Dor, E.; Banin, A. 1994. Visible and near-infrared $(0.4-1.1 \mu \mathrm{m})$ analysis of arid and semi-arid soils. Rem. Sens. Environ., 48, 261-274.

[8] Baumgardner, M. 1985. Reflectance properties of soils", Adv. Agron., 38, 1-44.

[9] Goldshleger, N.; Ben-Dor, E.; Benyamini, Y.; Blumberg, D.; Agassi, M. 2002. Spectral properties and hydraulic conductance of soil crusts formed by raindrop impact. Int. J. Remote Sens., 23, 3909-3920, 2002.

[10] Michael L. Whiting, Lin Li, Susan L. Ustin. 2003. Predicting water content using Gaussian model on soil spectra. Remote Sensing of Environment 89, 535-552.

[11] Fusun Balik Sanli , Yusuf Kurucu , Mustafa Tolga Esetlili, Sayg in Abdikan. 2008. Soil Moisture Estimation from RADARSAT -1, ASAR and PALSAR Data in Agricultural Fields of Menemen Plane of Western Turkey. The International Archives of the Photogrammetry, Remote Sensing and Spatial Information Sciences. Vol. XXXVII. Part B7. Beijing.

[12] Marion Pause, Karsten Schulz, Steffen Zacharias, and Angela Lauschd. 2012. Near-surface soil moisture estimation by combining airborne L-band brightness temperature observations and imaging hyperspectral data at the field scale. Journal of Applied Remote Sensing 063516-3 Vol. 6.

[13] Jian Peng, Hong Shen, San Wei He, Jian Sheng Wu. 2013. Soil moisture retrieving using hyperspectral data with the application of wavelet analysis. Environ Earth Sci ,69:279-288.

[14] Angström, A. 1925. The albedo of various surfaces of ground. Geogr. Ann., 7, 323-327.

[15] ASTM D 4642-87. 1987. Standard Test Method for Determination of Water Moisture Content of Soil by the Microwave Oven Method.

[16] Bach, H.; Mauser, W. 1994. Modelling and model verification of the spectral reflectance of soils under varying moisture conditions. In Proceedings of the International Geoscience and Remote Sensing Symposium, 1994. IGARSS '94. Surface and Atmospheric Remote Sensing: Technologies, Data Analysis and Interpretation, Pasadena, CA, USA, Volume 4, pp. 2354-2356.

[17] Lesaignoux, A.; Fabre, S.; Briottet, X. 2013. Influence of soil moisture content on spectral reflectance of bare soils in the 0.4-14 $\mu \mathrm{m}$ domain. Int. J. Remote Sens. , 34, 2268-2285.

[18] Soren-Nils Haubrock" , Sabine Chabrillat, Matthias Kuhnert, Patrick Hostert and Hermann Kaufmann. 2008. Surface soil moisture quantification and validation based on hyperspectral data and field measurements. Journal of Applied Remote Sensing, Vol. 2, 023552.

[19] Haubrock, S.; Chabrillat, S.; Lemmnitz, C.; Kaufmann, H. 2008. Surface soil moisture quantification models from reflectance data under field conditions. Int. J. Remote Sens. 29, 3-29.

[20] Attila Nagy , Péter Riczu, Bernadett Gálya, János Tamás 2014. Spectral estimation of soil water content in visible and near infra-red range. Eurasian Journal of Soil Science $3,163-171$. 
[21] Sophie Fabre, Xavier Briottet and Audrey Lesaignoux. 2015. Estimation of Soil Moisture Content from the Spectral Reflectance of Bare Soils in the 0.4-2.5 $\mu \mathrm{m}$ Domain. Sensors, 15, 3262-3281.

[22] Lobell, D.; Asner, G. 2002. Moisture Effects on Soil Reflectance. Soil Sci. Am. J., 66, 722-727.

[23] Berk, A.; Bernstein, L.S.; Anderson, G.P.; Acharya, P.K.; Robertson, D.C.; Chetwynd, J.H.; Adler-Golden, S.M. 1998. MODTRAN cloud and multiple scattering upgrades with application to AVIRIS. Remote Sens. Environ., 65, 367-375.

[24] Munsell Soil Color Chart 2009 Edition. Available online: https://nenc.gov.ua/old//GLOBE/Other/Munsell\%20soil $\% 20$ colour\%20chart.pdf (accessed on 15 April 2017). 